JMI Vol. 41 No. 2, Desember 2019

METAL INDONESIA

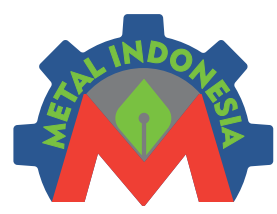

Journal Homepage:

http://www.jurnalmetal.or.id/index.php/imi

p-issn: 0126-3463

e-issn: 2548-673X

\title{
ANALISIS KUALITAS SEKOP DARI HASIL PRODUKSI INDUSTRI KECIL DAN MENENGAH (IKM) DI INDONESIA
}

\section{ANALYSYS OF SHOVEL QUALITY FROM SMALL AND MEDIUM INDUSTRIES (SMI) PRODUCTION IN INDONESIA}

\author{
Sina Jamilah*1, Gugum Gumilar ${ }^{2}$, Dewi Amalia ${ }^{3}$ \\ 1,2,3 Balai Besar Logam dan Mesin, Jalan Sangkuriang Nomor 12 Bandung \\ Email: ${ }^{1}$ sina-jamilah@kemenperin.go.id \\ *: kontributor utama
}

\begin{abstract}
Abstrak
Sekop merupakan salah satu peralatan yang biasanya digunakan dalam bidang pertanian dan konstruksi bangunan. Berdasarkan Standar Sekop SNI 0333:2011, kualitas bahan baku sekop diklasifikasikan menjadi kelas 1 (baja karbon menengah) dan kelas 2 (baja karbon). Penelitian ini bertujuan untuk mengetahui kualitas sekop hasil produksi IKM di beberapa kota di Indonesia dengan metode sampling. Fokus kegiatan penelitian ini yaitu pada kualitas bahan baku sekop yang dibatasi analisa pada uji kekerasan, uji beban, dan uji komposisi kimia. Hasil uji diolah untuk mendapatkan tren/karakter dari kualitas sekop hasil produksi IKM. Dari hasil uji kekerasan didapatkan $60 \%$ dari jumlah sampel berada pada tingkat kekerasan tinggi (20-39 HRC), $20 \%$ sampel memiliki tingkat kekerasan sedang (1-20 HRC), dan $20 \%$ sampel memiliki tingkat kekerasan yang rendah $(0-81 \mathrm{HRB})$. Hasil dari uji beban, sebanyak $87 \%$ sampel mengalami deformasi kurang dari $25 \mathrm{~mm}$ dan $13 \%$ sampel sekop mengalami patah pada bagian pegangan. Hasil pengujian komposisi kimia menunjukkan bahwa terdapat $40 \%$ sampel yang kandungan karbonnya rendah, namun sebagian besar adalah baja karbon rendah dengan kandungan karbon $<0,1 \%$. Baja karbon menengah hanya terdapat sebanyak $20 \%$, dan sisanya sebanyak $40 \%$ adalah baja karbon tinggi.
\end{abstract}

Kata kunci: kualitas sekop, bahan baku sekop, standar sekop SNI 0333:2011

\begin{abstract}
Shovel is equipment that usually used in agricultural and building construction. The quality of shovel raw materials based on SNI 0333;2011 is classified into carbon steel and medium carbon steel. This research aims to determine the quality of shovels that produced by Small and Medium Industries (SMI) in several cities in Indonesia by sampling methods with activity focuses on the quality of shovel raw materials and limited analysis to hardness, load, and chemical composition tests. The test results are analyzed to get the trend/character of shovel's quality. The hardness test results obtained $60 \%$ of the number of samples is at a high level of hardness (20-39 HRC), 20\% of the sample has a moderate level of hardness (1-20 HRC), and 20\% of the sample has a low level of hardness (0-81 HRB). The load test results, as many as $87 \%$ samples were deformed less than $25 \mathrm{~mm}$, and $13 \%$ as remaining of shovels samples had broken at the handle. The results of chemical composition tests show that $40 \%$ of samples are low carbon steels with a, $0.1 \%$ of carbon content, $20 \%$ of samples are medium carbon steel, and $40 \%$ samples as remaining are high carbon steel.
\end{abstract}

Keywords: shovel quality, material of shovel, shovel standard of SNI 0333:2011 


\section{PENDAHULUAN}

Sekop merupakan salah satu peralatan yang biasanya digunakan dalam bidang pertanian dan konstruksi bangunan, yang berfungsi untuk mengaduk dan mencampurkan bahan bangunan secara manual atau dengan menggunakan tangan. Sekop yang terbuat dari lempengan terbagi menjadi tiga bagian yaitu bagian kepala, bagian tengah, dan bagian pegangan. Pada bagian tengah merupakan bagian pegangan vertikal berupa garan yang terbuat dari kayu, sedangkan pada bagian pegangan atas/ pegangan horizontal ini berbentuk segitiga. Pada sisi kanan dan kirinya terbuat dari lempengan sedangkan bagian untuk memegang secara horizontal terdapat pula garan dari kayu. Cara menggunakan sekop ini yaitu dengan meletakan tangan kiri pada bagian tengah dan tangan kanan pada bagian pegangan atas. Lalu tinggal diayunkan untuk memindahkan pasir. Alat ini banyak digunakan oleh para pekerja bangunan untuk memudahkan kerja mereka dalam memindahkan pasir.

Sekop pasir berfungsi untuk mengeruk pasir, tanah atau kotoran serta pekerjaan lain yang letaknya presisi dekat dengan tanah sedangkan sekop taman selain dapat digunakan untuk menggali tanah dan mengeruk kotoran, lebih sering digunakan untuk memotong. Sekop diklasifikasikan berdasarkan bentuk dari daun sekop yaitu lancip, papak dan sepadan serta berdasarkan kelas 1 dan kelas 2 (Badan Standardisasi Nasional 2011).

Peralatan pertanian memiliki dua bagian, yaitu bagian kepala dan bagian pegangan. Peralatan pertanian memiliki berbagai macam bentuk. Bagian kepala terbuat dari berbagai macam material, bentuk, dan orientasi. Begitu pula bagian pegangan, bentuknya bervariasi dari yang pendek, panjang, ataupun lengkung (Lavis 2018).

Pemilihan peralatan pertanian bergantung pada luas area, profil pengguna (usia, jenis kelamin, kekuatan, dll), dan waktu yang diperlukan untuk menyelesaikan pekerjaan. Sekop memiliki bentuk dan ukuran yang berbeda-beda untuk menyesuaikan dengan berbagai macam penggunaan seperti menggali, mengangkat, atau memindahkan tanah/pasir. (Niemiera 2006).

Ashburner dan Kienzle yang merupakan anggota Food and Agriculture Organization (FAO) telah melakukan penelitian bahwa pemilihan peralatan pertanian yang sesuai dalam keadaan darurat sangat diperlukan. Penelitian dilakukan di negara berkembang khususnya di daerah sub-sahara Afrika. Berdasarkan Standar Kenya KS 204 : 1992 Specification for shovels, sekop untuk pertanian harus terbuat dari baja karbon menengah dengan komposisi unsur karbon sebesar 0,40 - 0,65 \% dan kekerasan sebesar 39 - 48 HRC (Ashburner and Kienzle 2013). Hal ini tentu disesuaikan dengan kondisi lahan pertanian di daerah Afrika. Jika dibandingkan dengan Standar SNI 0333:201, maka kategori ini termasuk pada Kelas 1.

Kualitas bahan baku pada saat pembuatan sekop sangat berpengaruh terhadap kualitas sekop tersebut. Penggunaan bahan baku berkualitas rendah dari komponen bekas akan menghasilkan produk dengan kualitas rendah pula (Suryanto 2017). Oleh karena itu, perlu dilakukan pemilihan material yang baik. SNI 0333:2011 merupakan Standar Nasional Indonesia untuk sekop yang menjelaskan syarat mutu dan metode uji nya. Dengan mengacu pada SNI tersebut, diharapkan produk sekop yang dihasilkan dari IKM di Indonesia dapat bersaing secara kualitas.

Penelitian ini bertujuan untuk mengetahui kualitas sekop hasil produksi IKM di Indonesia. Manfaat dari penelitian ini adalah sebagai gambaran kualitas sekop yang dihasilkan oleh IKM di Indonesia. Kegiatan ini fokus pada kualitas bahan baku sekop sehingga analisis dibatasi pada uji kekerasan, uji beban, dan uji komposisi kimia.

\section{METODOLOGI}

Metode penelitian ini adalah dengan cara melakukan sampling terhadap sekop yang diproduksi oleh Industri Kecil dan Menengah (IKM) di beberapa kota di Indonesia.

Tahapan penelitian yang dilakukan dapat dilihat pada Gambar 1 di bawah ini. 


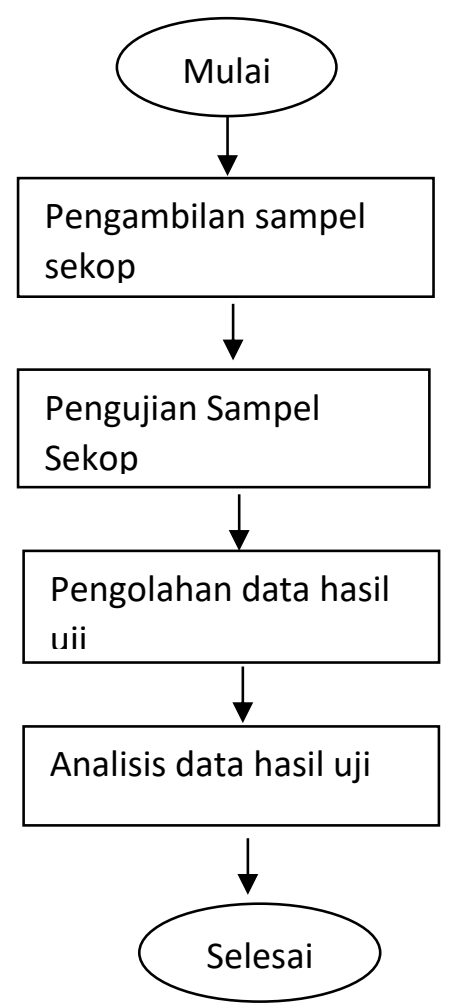

Gambar 1. Diagram blok tahapan analisis kualitas sekop hasil produksi IKM di Indonesia

Indonesia memiliki standar yang mengatur kualitas sekop yaitu SNI 0333:2011. Syarat mutu yang harus dipenuhi pada SNI tersebut adalah dimensi sekop, konstruksi sekop, bahan sekop, dan sekop tidak berubah bentuk lebih dari $25 \mathrm{~mm}$ setelah diberi beban. Pada SNI ini perlu dilakukan uji verifikasi untuk mengetahui dimensi dan jenis sekop yaitu sekop bentuk lancip, bentuk papak, atau bentuk sepadan. Uji selanjutnya adalah uji kekerasan dan uji beban.

Namun demikian, penelitian ini fokus pada kualitas bahan sekop sehingga pembahasan dibatasi pada pengujian sampel berupa uji kekerasan, uji beban, dan uji komposisi kimia.

Hasil uji diolah untuk mendapatkan tren/karakter dari kualitas sekop hasil produksi IKM ini. Kemudian hasil uji tersebut dibandingkan dengan standar sekop yaitu SNI 0333:2011.

Bahan uji yang digunakan pada penelitian ini adalah sampel sekop yang diambil dari 9 (Sembilan) IKM di beberapa kota yaitu Surabaya, Gresik, Klaten, dan Kabupaten Bandung.
Pada Standar SNI 0333:2011 dijelaskan bahwa syarat mutu untuk beberapa pengujian adalah sebagai berikut:

\section{Uji Kekerasan}

Sekop kelas 1 harus memiliki kekerasan 3946 HRc, sedangkan Sekop kelas 2 harus memiliki kekerasan 30-39 HRc.

Pengujian kekerasan dilakukan pada temperatur $24,3{ }^{\circ} \mathrm{C}$ dan kelembaban $61 \%$ dengan menggunakan mesin uji kekerasan Rockwell Future Tech LC 200RB SN LCR 0729.

\section{Uji Beban}

Sekop kelas 1 harus dapat menahan beban sebesar $40 \mathrm{~kg}$ dan kelas 2 dapat menahan beban sebesar $25 \mathrm{~kg}$ dengan waktu pembebanan masing-masing selama 3 menit, Setelah pembebaban sekop tidak boleh mengalami perubahan bentuk tetap sebanyak $25 \mathrm{~mm}$ diukur dari titik tengah pemegang (klem) daun sekop.
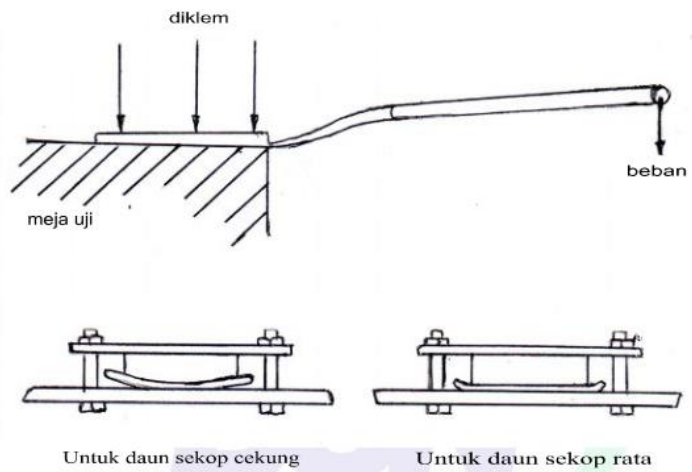

Gambar 2. Cara Uji Beban sesuai dengan SNI 0333:2011

Pengujian beban dilakukan dengan cara memberi beban pada sampel sekop sebesar $25 \mathrm{Kg}$ selama 3 menit kemudian diukur besar deformasinya.

\section{Uji Komposisi Kimia}

Sekop kelas 1 harus terbuat dari baja karbon menengah dengan spesifikasi kekerasan 3946 HRc, sedangkan Sekop kelas 2 harus terbuat dari baja karbon dengan spesifikasi kekerasan 30-39 HRc.

Pengujian komposisi kimia dilakukan pada temperature $23,8{ }^{\circ} \mathrm{C}$ dan kelembaban $56 \%$ dengan menggunakan mesin uji komposisi kimia PMI Master Smart 57T0028 No. Probe 66T0020. 


\section{HASIL DAN PEMBAHASAN}

Setiap sampel sekop dalam penelitian ini dilakukan pengujian berdasarkan Standar SNI 0333:2011 yaitu uji kekerasan, uji beban, dan uji komposisi kimia. Hasil pengujian secara keseluruhan ditampilkan pada Tabel 1, sedangkan tren hasil uji pada setiap jenis pengujian ditampilkan dalam Gambar 3 - 5.

Tabel 1. Hasil Uji Sampel Sekop

\begin{tabular}{|c|c|c|c|c|c|}
\hline \multirow{2}{*}{ No. } & \multirow{2}{*}{ SAMPEL } & $\begin{array}{c}\text { UII } \\
\text { KEKERASAN } \\
\text { (RATA-RATA) }\end{array}$ & \multicolumn{2}{|c|}{ UII BEBAN } & \multirow{2}{*}{$\begin{array}{c}\begin{array}{c}\text { KOMPOSISI } \\
\text { KIMIA }\end{array} \\
\text { Unsur C }\end{array}$} \\
\hline & & Daun Sekop & $\underset{(\mathrm{mm})}{\text { Deformasi }}$ & Keterangan & \\
\hline 1 & Sampel A & 27.07 HRC & 6.44 & - & 0.683 \\
\hline 2 & Sampel B & 87.04 HRB & 5.50 & - & 0.0711 \\
\hline 3 & Sampel C & 33.42 HRC & 13.41 & - & 0.599 \\
\hline 4 & Sampel D & 66.47 HRB & 24.25 & - & 0.192 \\
\hline 5 & Sampel E & 31.41 HRC & 4.20 & - & 0.463 \\
\hline 6 & Sampel F & 37.61 HRC & 5.13 & - & 0.634 \\
\hline 7 & Sampel G & $26.34 \quad$ HRC & 11.00 & - & 0.659 \\
\hline 8 & Sampel H & $32.33 \quad$ HRC & 2.21 & - & 0.653 \\
\hline 9 & Sampel I & $33.70 \quad$ HRC & 4.22 & - & 0.636 \\
\hline 10 & Sampel I & 22.69 HRC & 3.10 & - & 0.695 \\
\hline 11 & Sampel K & $22.42 \quad$ HRC & 5.08 & - & 0.500 \\
\hline 12 & Sampel L & $66.16 \quad$ HRB & 24.25 & - & 0.0564 \\
\hline 13 & Sampel M & 20.09 HRC & - & $\begin{array}{c}\text { Patah pada bagian } \\
\text { pegangan plastik sekop }\end{array}$ & 0.189 \\
\hline 14 & Sampel N & 37.15 HRB & 20.28 & - & 0.0185 \\
\hline 15 & Sampel O & 13.18 HRC & - & $\begin{array}{l}\text { Patah pada bagian } \\
\text { pegangan plastik sekop }\end{array}$ & 0.0870 \\
\hline
\end{tabular}

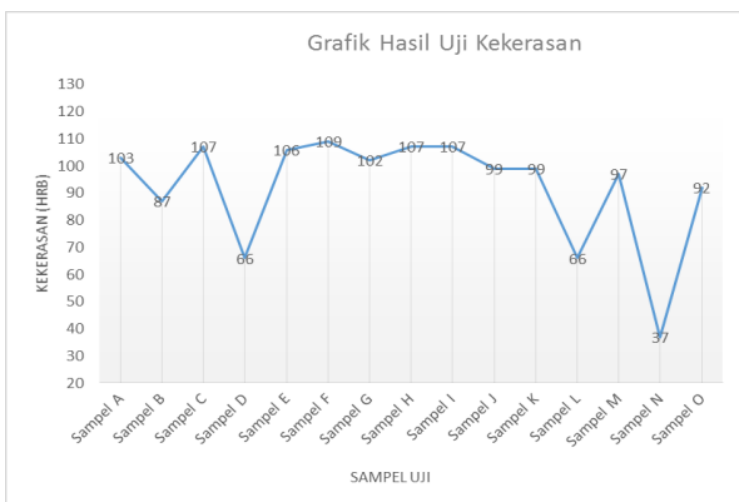

Gambar 3. Grafik Hasil Uji Kekerasan

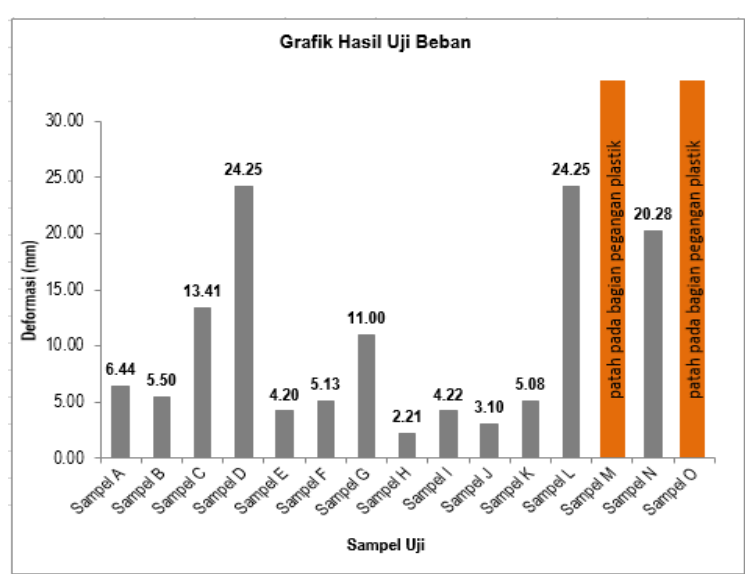

Gambar 4. Grafik Hasil Uji Komposisi Kimia

\section{Uji kekerasan}

Kekerasan material secara umum menentukan ketahanan terhadap gesekan, aus, penetrasi, dan kemampuan untuk dilakukan proses pemesinan atau pembentukan (Agricultural Engineering Service (AGSE) 2001).

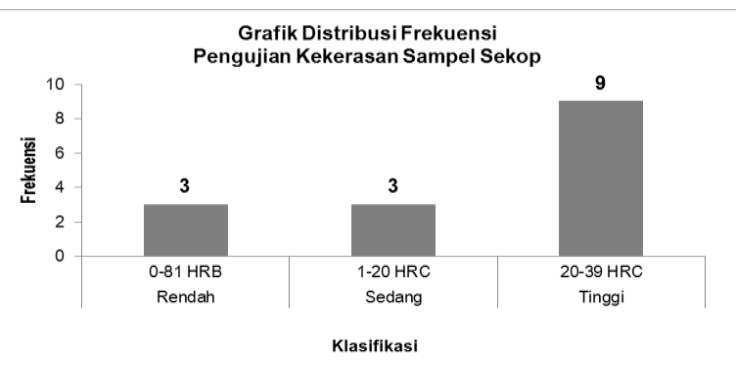

Gambar 5. Grafik Distribusi Frekuensi Pengujian Kekerasan Sampel Sekop

Berdasarkan Gambar 6, klasifikasi dibagi menjadi 3 bagian yaitu rendah untuk 0-81 HRB, sedang untuk 1-20 HRC, dan tinggi untuk 20-39 HRC. Dapat dilihat dari grafik bahwa 60 $\%$ dari jumlah sampel berada pada Klas No.3 dengan tingkat kekerasan tinggi.

Namun demikian, masih ada $20 \%$ sampel dengan tingkat kekerasan sedang dan 20 $\%$ sampel dengan tingkat kekerasan rendah. Perlu adanya upaya peningkatan kualitas supaya produk IKM dapat bersaing secara kualitas.

Salah satu metode untuk meningkatkan kualitas produk adalah dengan proses pengerasan permukaan melalui metode karbonisasi. Proses ini dapat meningkatkan kekerasan pada permukaan material logam (Schneider and Chatterjee 2013).

Pada saat komposisi karbon meningkat ketika proses perlakuan panas, maka kekerasan dan kekuatan material akan meningkat namun elastisitas material akan menurun (Agricultural Engineering Service (AGSE) 2001). Oleh karena itu perlu adanya pembatasan penambahan karbon sehingga material tidak menjadi getas.

Heru Suryanto melakukan penelitian mengenai teknologi karbonisasi untuk meningkatkan kualitas produk pandai besi. Dari penelitian tersebut, kekerasan produk berhasil ditingkatkan sampai 5 (lima) kali kekerasan baja karbon rendah. Kekerasan mencapai 500 $\mathrm{kg} / \mathrm{mm}^{2}$ atau setara dengan 49 HRC mencapai kedalaman $600 \mu \mathrm{m}$ pada karbonisasi dengan temperatur $950{ }^{\circ} \mathrm{C}$. (Suryanto 2017). 


\section{Uji Beban}

Uji beban dilakukan untuk mengevaluasi efek dari pemberian beban terhadap bentuk suatu material/produk ("Deformation Testing" 2019).

Elastisitas (ductility) menunjukkan seberapa banyak suatu material berubah bentuk ketika diregangkan. Sifat mekanik ini mewakili kemampuan material untuk mengakomodasi deformasi tanpa terjadi kegagalan. Material dengan keuletan yang lebih tinggi menyiratkan kemampuannya yang lebih besar untuk menahan beban benturan (Agricultural Engineering Service (AGSE) 2001).

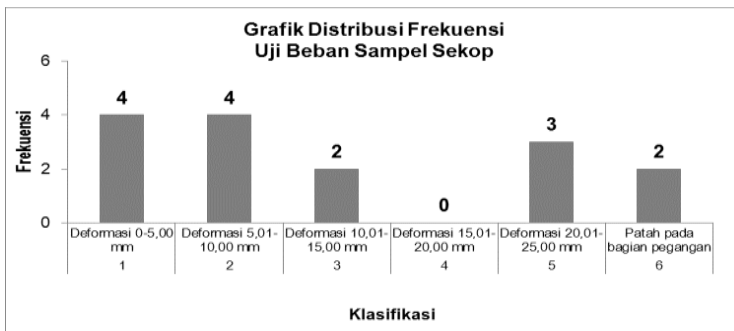

Gambar 6. Grafik Distribusi Frekuensi Uji Beban Sampel Sekop

Pada saat dilakukan uji beban, sebanyak $87 \%$ memenuhi syarat mutu SNI Sekop sesuai dengan hasil uji pada Gambar 7. Dari hasil pengujian, $53 \%$ sampel sekop yang lulus uji beban mengalami deformasi yang cukup kecil yaitu antara 0 sampai $10,00 \mathrm{~mm}$, meskipun ada $20 \%$ sampel sekop yang deformasinya hampir mencapai batas maksimal syarat mutu SNI Sekop. Selain itu, ada $13 \%$ sampel sekop yang patah pada bagian pegangan plastik.

Semakin keras material, maka akan semakin kecil deformasi yang terjadi ketika diberi beban. Dengan meningkatnya kekerasan material maka produk yang dihasilkan tidak akan mudah terdeformasi (Suryanto 2017).

Patahnya sampel sekop yang berada pada daerah pegangan plastik disebabkan oleh kualitas material plastik yang kurang baik. Pegangan plastik tersebut tidak dapat menahan beban yang diberikan.

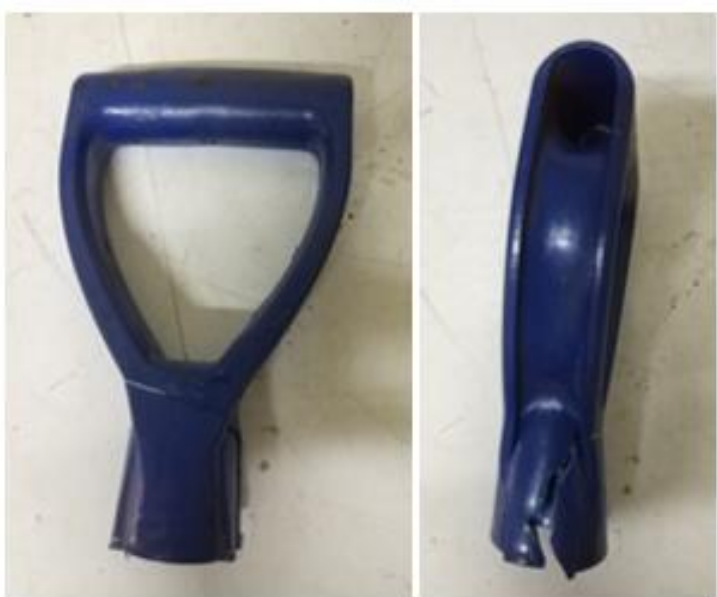

Gambar 7. Patah pada Pegangan Plastik

\section{Uji Komposisi Kimia}

Hasil uji komposisi kimia ditunjukkan pada Tabel 2. Sesuai dengan syarat mutu SNI 0333:2011 yang menyatakan bahwa sekop harus terbuat dari baja karbon, maka parameter komposisi kimia yang dianalis adalah unsur karbon (C). Baja karbon dibagi dalam tiga jenis berdasarkan kandungan karbon pada suatu material. Jenis-jenis baja karbon tersebut adalah baja karbon rendah dengan kandungan karbon < $0,25 \%$, baja karbon menengah dengan kandungan karbon $0,25-0,6 \%$, dan baja karbon tinggi dengan kandungan karbon 0,6 1,4\% (Callister and Rethwisch 2011)

Tabel 2. Hasil Uji Komposisi Kimia Sampel Sekop

\begin{tabular}{|c|c|c|c|c|c|c|c|c|}
\hline apel & $\mathrm{Fe}$ & c & $\mathrm{Si}$ & $\mathrm{Mn}$ & $\mathbf{P}$ & $\mathrm{s}$ & $\mathrm{Cr}$ & Mo \\
\hline Sampel A & 98,2 & 0,636 & 0,129 & 0,662 & 0,0163 & 0,0332 & 0,0262 & $<0,0030$ \\
\hline Sampel B & 98,1 & 0,653 & 0,231 & 0,911 & 0,0145 & 0,0173 & 0,0059 & $<0,0030$ \\
\hline Sampelc & 97,9 & 0,436 & 0,171 & 1,190 & 0,0240 & 0,0268 & 0,0062 & 0,0030 \\
\hline Sampel D & 97,7 & 0,711 & 0,005 & 1,990 & 0,0250 & 0,0020 & 0,2980 & 0,0030 \\
\hline Sampel E & 97,7 & 0,659 & 0,576 & 0,935 & 0,0196 & 0,0121 & 0,0197 & 0,0030 \\
\hline Sampel F & 98,5 & 0,500 & 0,152 & 0,621 & 0,0156 & 0,0376 & 0,0050 & $<0,0030$ \\
\hline Sampel G & 7,8 & 0,695 & 0,545 & 0,835 & 0,0210 & 0,0930 & 0,0193 & 0,0030 \\
\hline Sampel H & 97,7 & 0,634 & 0,538 & 0,984 & 0,0182 & 0,0052 & 0,0186 & 0,0030 \\
\hline Sampel I & 97,6 & 0,0683 & 0,255 & 1,340 & 0,0220 & 0,0052 & $<0,0050$ & 0,0030 \\
\hline Sampel I & 97,8 & \begin{tabular}{l|l|}
0,599 \\
\end{tabular} & \begin{tabular}{|l|}
0,528 \\
\end{tabular} & 0,886 & 0,0199 & 0,0031 & 0,0363 & 0,0030 \\
\hline Sampel K & 99,0 & \begin{tabular}{l|l|}
0,0192 \\
\end{tabular} & $<0,0050$ & 0,723 & 0,0283 & 0,0088 & 0092 & 0,0030 \\
\hline Sampel L & 98,4 & \begin{tabular}{|c|}
0,087 \\
\end{tabular} & |0,0401 & 1,220 & 0,0217 & 0,0020 & 0,0082 & $<0,0030$ \\
\hline Sampel M & 99,7 & 0,0185 & $<0,0050$ & 0,0885 & 0,0175 & 0,0058 & 0,0178 & $<0,0030$ \\
\hline Sampel N & 99,0 & 0,189 & 0,0079 & 0,699 & 0,0148 & 0,0020 & 0,0173 & 0,0030 \\
\hline Sampel 0 & 99,7 & 0,0564 & $\begin{array}{ll}0,0321 \\
\end{array}$ & 0,0809 & 0,0160 & 0,0021 & 0,0168 & $<0,0030$ \\
\hline Sampel & $\mathbf{N i}$ & Al & co & $\mathrm{Cu}$ & Nb & $\mathrm{Ti}$ & v & w \\
\hline Sampel A & 0,0396 & 0,0099 & 0,0154 & 0,1480 & 0,0050 & 0,0013 & 0,0020 & $<0,0400$ \\
\hline Sampel B & 0,0066 & 123 & 0,0022 & 0,0069 & 0,0060 & 0,0023 & 0,0017 & $<0,0400$ \\
\hline Sampel c & 0,0257 & 102 & $<0,0020$ & 0,0371 & 0,0094 & 0,0025 & 0,0024 & 0,0400 \\
\hline Sampel D & 0,0090 & 0,0345 & 0,0025 & 0,0110 & 0,0389 & 0,0231 & 0,0017 & 0,0400 \\
\hline Sampel E & $<0,0050$ & 0,0030 & $<0,0020$ & 0,0056 & 0,0071 & 0,0032 & 0,0509 & $<0,0400$ \\
\hline Sampel F & 0,0073 & 0,0206 & 0,0059 & 0,0441 & 0,0051 & 0,0023 & 0,0017 & $<0,0400$ \\
\hline Sampel G & $<0,0050$ & 0,0043 & 0,0034 & 0,0059 & 0,0055 & 0,0300 & 0,0447 & $<0,0400$ \\
\hline Sampel H & 0,0103 & 0,0023 & 0,0040 & 0,0136 & 0,0087 & 0,0370 & 0,0589 & $<0,0400$ \\
\hline Sampel I & $<0,0050$ & 0,0061 & $<0,0020$ & 0,0052 & 0,0054 & 0,0036 & 0,0022 & $<0,0400$ \\
\hline Sampel I & $<0,0050$ & 0,0037 & $<0,0020$ & 0,0072 & 0,0074 & 0,0037 & 0,0561 & $<0,0400$ \\
\hline Sampel K & $<0,0050$ & 0,0309 & $<0,0020$ & 0,0080 & 0,0048 & $\begin{array}{l}3 \\
3\end{array}$ & 0,0014 & $<0,0400$ \\
\hline Sampel L & & 0353 & 0,0027 & 0,1320 & 0,0027 & \begin{tabular}{|l|l} 
& 0,0541 \\
\end{tabular} & 0,0024 & $<0,0400$ \\
\hline Sampel M & $<0,0050$ & 0,0328 & 0,0022 & 0,1096 & 0,0142 & 0,0190 & 0,0010 & $<0,0400$ \\
\hline Sampel N & 0,0098 & 0,0350 & $<0,0020$ & 0,0089 & $<0,0020$ & $<0,010$ & 0,0015 & $<0,0400$ \\
\hline Sampel 0 & $<0,0050$ & 0,0202 & 0,0022 & 0,0080 & 0,0051 & 0,0013 & 0,0021 & $<0,0400$ \\
\hline
\end{tabular}




\begin{tabular}{|c|c|r|r|r|r|r|c|}
\hline Sampel & Pb & \multicolumn{1}{c|}{ Sn } & \multicolumn{1}{c|}{ B } & \multicolumn{1}{c|}{ Ca } & \multicolumn{1}{c|}{ Zr } & \multicolumn{1}{c|}{ As } & Bi \\
\hline Sampel A & $<0,0150$ & 0,0049 & 0,0010 & $<0,0010$ & $<0,0020$ & 0,0194 & $<0,0250$ \\
\hline Sampel B & $<0,0150$ & 0,0098 & $<0,0010$ & $<0,0010$ & $<0,0020$ & 0,0054 & $<0,0250$ \\
\hline Sampel C & $<0,0150$ & 0,0123 & 0,0020 & $<0,0010$ & 0,0033 & 0,0418 & $<0,0250$ \\
\hline Sampel D & $<0,0150$ & 0,0048 & 0,0015 & $<0,0010$ & 0,0027 & 0,0121 & $<0,0250$ \\
\hline Sampel E & $<0,0150$ & 0,0032 & $<0,0010$ & $<0,0010$ & 0,0021 & 0,0134 & $<0,0250$ \\
\hline Sampel F & $<0,0150$ & $<0,0020$ & $<0,0010$ & $<0,0010$ & $<0,0020$ & 0,0101 & $<0,0250$ \\
\hline Sampel G & $<0,0150$ & 0,0028 & 0,0010 & 0,0010 & 0,0020 & 0,0112 & $<0,0250$ \\
\hline Sampel H & $<0,0150$ & 0,0079 & 0,0010 & $<0,0010$ & 0,0030 & 0,0088 & $<0,0250$ \\
\hline Sampel I & $<0,0150$ & 0,0021 & 0,0013 & $<0,0010$ & 0,0026 & 0,0108 & $<0,0250$ \\
\hline Sampel I & $<0,0150$ & 0,0043 & $<0,0010$ & $<0,0010$ & 0,0022 & 0,0087 & $<0,0250$ \\
\hline Sampel K & $<0,0150$ & 0,0062 & 0,0014 & $<0,0010$ & $<0,0020$ & 0,0072 & $<0,0250$ \\
\hline Sampel L & $<0,0150$ & 0,0073 & 0,0017 & 0,0022 & $<0,0020$ & 0,0182 & $<0,0250$ \\
\hline Sampel M & $<0,0150$ & 0,0094 & 0,0015 & $<0,0010$ & $<0,0020$ & 0,0197 & $<0,0250$ \\
\hline Sampel N & $<0,0150$ & 0,0032 & $<0,0010$ & $<0,0010$ & $<0,0020$ & $<0,0050$ & $<0,0250$ \\
\hline Sampel O & $<0,0150$ & 0,0025 & 0,0010 & 0,0047 & $<0,0020$ & 0,0070 & $<0,0250$ \\
\hline
\end{tabular}

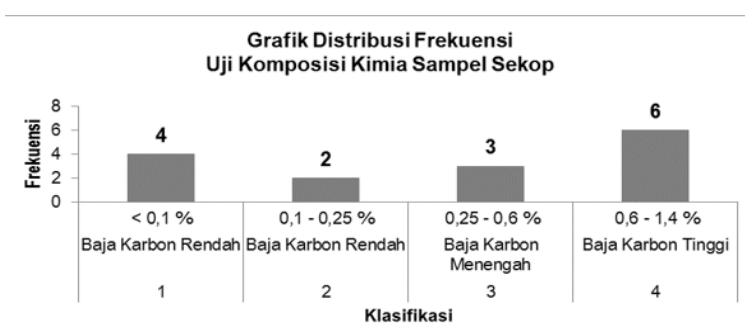

Gambar 8. Grafik Distribusi Frekuensi Uji Komposisi Kimia Sampel Sekop

Hasil pengujian sampel sekop pada Gambar 9 menunjukkan bahwa terdapat $40 \%$ sampel yang kandungan karbonnya rendah. Namun, sebanyak dua pertiga bagiannya adalah baja karbon rendah dengan kandungan karbon < $0,1 \%$. Baja karbon menengah hanya sebanyak $20 \%$, dan sisanya sebanyak $40 \%$ adalah baja karbon tinggi.

Kadar karbon dalam suatu material berpengaruh terhadap kekerasan material tersebut. Semakin tinggi kadar karbon, maka kekerasan material akan semakin tinggi juga [adnan,2009]. Dari hasil pengujian komposisi kimia, diketahui terdapat $40 \%$ sampel sekop memiliki kekerasan yang rendah dan sedang. Hal tersebut disebabkan oleh unsur karbon pada materialnya berkisar antara $0-0,25 \%$ (baja karbon rendah). Grafik hubungan nilai unsur karbon dan nilai kekerasan dapat dilihat pada Gambar 10, yang menunjukkan bahwa koefisien determinasinya $\mathrm{R}^{2}=0.5891$, sehingga dapat diketahui $58.91 \%$ nilai rata-rata kekerasan sampel sekop ditentukan oleh nilai unsur karbon. Sebanyak $41.09 \%$ adalah faktorfaktor lainnya yang mempengaruhi besaran nilai kekerasan material sekop, seperti proses pembuatan sekop, proses perlakuan lanjutan, dan juga unsur lainnya yang sengaja ditambahkan [Alrashdan, et al,2018].

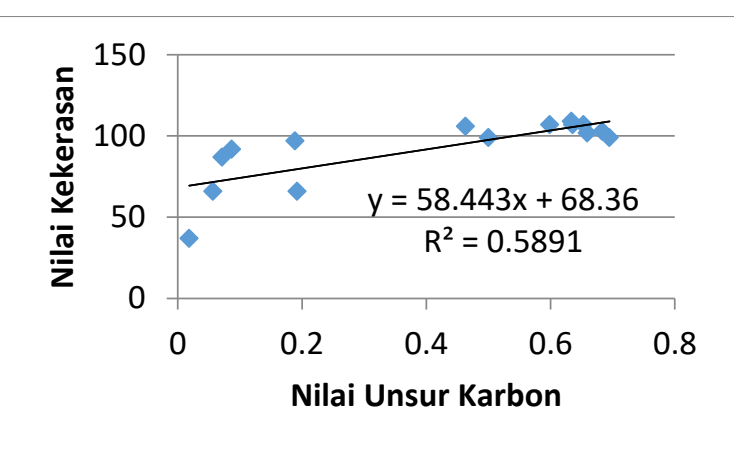

Gambar 10. Grafik hubungan nilai unsur karbon dan nilai kekerasan

Komposisi karbon untuk bahan baku peralatan pertanian atau konstruksi bangunan bervariasi sesuai dengan kebutuhan. Hasil penelitian di daerah Afrika adalah sebagai berikut; kandungan karbon 0,15-0,25\% cocok digunakan untuk perkakas tangan pertanian, seperti soket atau tali sekop dan lain-lain. Untuk keperluan konstruksi dapat menggunakan material dengan kandungan karbon 0,25 - 0,5 $\%$. Untuk peralatan pertanian seperti cangkul, sekop, garpu, parang, arit, dan kapak sebaiknya menggunakan material dengan kandungan karbon sebesar 0,40-0,5\%. Untuk alat-alat seperti cangkul, kapak, parang, dan sabit dapat menggunakan material dengan kandungan karbon 0,5-0,6\% (Agricultural Engineering Service (AGSE) 2001).

Peralatan yang dibuat dari baja karbon tinggi cocok digunakan untuk menggali, menanam, memotong, dan menyiangi. Baja karbon tinggi adalah paduan yang terbuat dari besi dan sejumlah kecil karbon yang dikombinasikan pada suhu yang sangat tinggi. Bahan-bahan ini dipanaskan dan ditempa kembali, dicampur besi dengan butiran karbon untuk membentuk baja yang kuat (Lavis 2018).

Dari hasil penelitian ini, maka IKM dapat mengetahui kualitas sekop yang telah diproduksi. IKM perlu memperbaiki proses pembuatan sekop dan mempertimbangkan penggunaan bahan baku yang sesuai sehingga sekop yang dihasilkan sesuai dengan standar SNI.

\section{KESIMPULAN}

Hasil uji kekerasan, uji beban, dan uji komposisi pada sampel sekop dari produksi IKM di Indonesia memiliki nilai yang bervariasi. Jika dibandingkan dengan Standar Sekop SNI 0333:2011, maka ada sebagian sampel yang masuk standar dan ada juga yang tidak masuk standar. 
Hasil uji kekerasan menunjukkan bahwa sebagian besar sampel memiliki kekerasan yang tinggi (20-39 HRC), namun masih ada sampel dengan tingkat kekerasan rendah (0-81 HRB) yang jumlahnya sama dengan sampel yang memiliki tingkat kekerasan sedang (1-20 HRC).

Pada saat dilakukan uji beban, hampir semua sampel memenuhi standar SNI 0333:2011 meskipun variasi nilainya cukup lebar. Ada $13 \%$ sampel yang patah pada bagian pegangan plastik pada saat uji beban ini.

Hasil pengujian komposisi kimia, baja karbon menengah paling sedikit digunakan sebagai bahan baku. Penggunaan baja karbon rendah dan baja karbon tinggi adalah masingmasing sebanyak $40 \%$.

Dari hasil pengujan ini, dapat disimpulkan bahwa bahan baku yang digunakan oleh IKM di beberapa kota di Indonesia untuk membuat sekop cukup bervariasi. Pemilihan bahan baku ini berpengaruh terhadap kualitas sekop. Namun hasil ini belum dapat menggambarkan kualitas sekop secara keseluruhan karena perlu mempertimbangkan uji verifikasi untuk mengetahui kesesuaian dimensi dan bentuk sekop. Oleh karena itu perlu adanya penelitian lanjutan mengenai uji verifikasi.

\section{SARAN}

Perlu dilakukan penelitian lebih lanjut mengenai analisis bentuk dan dimensi sekop, serta analisis terhadap faktor yang mempengaruhi terhadap kekerasan yang dapat dijadikan sebagai standard kekerasan sekop di Indonesia

\section{UCAPAN TERIMA KASIH}

Penulis mengucapkan terima kasih kepada Shinta Virdhian sebagai Kepala Bidang Penelitian dan Pengembangan, Pujiyanto sebagai Kepala Seksi Pemesinan dan Pengelasan di Balai Besar Logam dan Mesin, dan Eva Afrilinda sebagai Peneliti di Balai Besar Logam dan Mesin yang telah membimbing penulis sehingga penelitian ini dapat terselenggara.

\section{DAFTAR PUSTAKA}

Agricultural Engineering Service (AGSE). 2001. Guidelines for the Technical Specifications and Procurement of Agricultural Hand Tools.

Alrshdan,Khaled R., Ali, FouadA., Khedr, Mohey M Alden. 2018. "Enhancing the
Mechanical Properties of Carbon Steel (AISI 1040) by Optimizing Heat Treatment", Material Science: An Indoan Journal, Volume 16(2).

Ashburner, John E., and Josef Kienzle. 2013. Agricultural Hand Tools in Emergencies: Guidelines for Technical and Field Officers. Rome: Food And Agriculture Organization of The United Nations.

Badan Standardisasi Nasional. 2011. "SNI 0333:2011 Sekop - Syarat Mutu Dan Metode Uji."

Calik, Adnan. 2009. "Effect of Cooling rate on hardness and microstructure of AISI 1020, AISI 1040 and AISI 1060 Steels", International Journal of Physical Sciences Vol 9 (9), pp.514-518

Callister, William D, and David G Rethwisch. 2011. Materials Science and Engineering.

"Deformation Testing." 2019. Accessed October 26.

https://www.ametektest.com/learningzone /testtypes/deformation-testing.

Lavis, Cathie. 2018. "How to Select Quality Landscape and Garden Tools." Kansas State University, 1-4.

Niemiera, Alex X. 2006. "Gardening Equipment." Virginia Polytechnic Institute and State University.

Schneider, Michael J, and Madhu S Chatterjee. 2013. "Introduction to Surface Hardening of Steels." ASM Handbook 4.

Suryanto, Heru. 2017. "Perbaikan Kualitas Produk Pande Besi Melalui Teknologi Karbonisasi." ResearchGate, no. March. 